\title{
The role of negative pressure wound therapy in the treatment of pilonidal disease
}

\author{
Jan Chmielecki, Josephine Ferenc, Tomasz Banasiewicz
}

\section{ORGINAL ARTICLE}

\begin{abstract}
Pilonidal disease is a particularly difficult disorder to treat. Guidelines and recommendations for the treatment of pilonidal disease neglect the use of negative pressure wound therapy (NPWT), but studies strongly support the role of NPWT in preventing surgical site infection in high-risk patients.

During a webinar on the pilonidal disease, we asked 51 participants to complete a questionnaire about the treatment of pilonidal disease. They answered questions about treatment practices for patients with a pilonidal disease, and the use of NPWT.

The study showed that a relatively large number of surgeons use NPWT to treat patients with the pilonidal disease. The majority of them are satisfied with maintaining the tightness and effectiveness of a vacuum dressing and would use the single-use NPWT systems if they were more easily available and affordable. It seems that the NPWT in the pilonidal disease is increasingly used and this method is gaining popularity among practitioners.
\end{abstract}

Keywords-pilonidal disease, pilonidal cyst, negative pressure wound therapy, NPWT, vacuum therapy,

\section{INTRODUCTION}

$\mathbf{T}$ HE pilonidal disease is a particularly difficult disorder to treat. It is significantly more likely to affect men more than women and it is worth noting that it often presents during periods of increased personal and professional activity 1 The chronic and recurrent nature of pilonidal disease effectively decreases patient's quality of life and often poses a challenge to surgeons.

Previously published guidelines and recommendations for the treatment of pilonidal disease neglect the use of negative pressure wound therapy (NPWT) as a potential therapeutical approach! 1, 3 While treatment guidelines outlined by the Italian Society of Colorectal Surgery ${ }^{4}$ reference a study on the use of NPWT by Biter et al., 5 the technique is not actually officially recommended by international societies in any of the current management guidelines.

NPWT as a treatment regimen for the pilonidal disease has been reported in the literature since 2003. Duxbery et al. first described a case of a patient who was treated with a vacuum dressing after pilonidal sinus excision over an

Manuscript received 10.03.2019; revised 04.04.2019. This work did not receive any financial support. Authors declare no conflict of interest.

Author affiliations: The General and Endocrine Surgery and Gastroenterological Oncology Department, K. Marcinkowski University of Medical Sciences, Poznań, Poland, (JC, TB)

*Correspondence to: Jan Chmielecki: jan.j.chmielecki@gmail.com open wound ${ }^{6}$ The patient's wound healed over a period of 8 weeks and the recurrence wasn't observed in one year. In the following years, publications about successfully treated patients using NPWT started to appear. ${ }^{7 \cdot 11}$ Mainly NPWT had been applied after wide excisions to stimulate healing and the production of granulation tissue, ${ }^{7} \sqrt{9}$ but Lynch et al. also described the use of NPWT to support the healing of intermediate thickness skin grafts following the excision of pilonidal sinus! 10 In 2007, Bandewald et al. published a report on pilonidal disease and suggested that primary NPWT may be a simpler alternative to more complicated procedures (such as primary closures with flap reconstructions) ${ }^{[1]}$ Further researches established that the use of NPWT is helpful in reducing the incidence of surgical site infection and wound dehiscence in the setting of wounds that have been primary closed ${ }^{[12}$ NPWT is also successfully used to treat certain complications following surgical intervention of a pilonidal sinus, such as the development of wound dehiscence after Limberg flap. 13

At our medical center, we have been relying on the use of NPWT to treat patients with pilonidal disease for over 10 years. Initially, we restricted the application of NPWT to the wounds with extensive exudation, lacking adequate granulation tissue development, and those in which we did not observe the progression of healing (Fig. 2, left). The positive effects of the chosen therapy led us to implement the use of vacuum dressings more widely, immediately following the surgical excision. We are also keen on using small, comfortable and portable, disposable devices (Fig. 2, right). In addition to the fact that the procedure improves wound healing, the benefits of NPWT are further substantiated by patients reporting less pain during the early postoperative period. 14 Procedurally, the vacuum dressing is first applied in the operating room and then changed every 3 days, or earlier in case of extensive wound drainage (Fig. 3. left). It is important to remember not to use disposable dressings which have been filled by drainage as it compromises the vacuum function of NPWT. Experience has shown that there are particular cases requiring more fastidious care. Due to the uncomfortable location, maintaining dressing tightness might sometimes be problematic (the wound drape alone is not enough to facilitate air-tightness). We have found that the use of ostomy paste helps the film to adhere more tightly to the wound (Fig. 1). 
Table I

QUESTIONNAIRE COMPRISED OF A SURVEY ANSWERED IN REAL TIME BY 51 RESPONDENTS DURING A WEBINAR HELD ON 12.03.2019

\begin{tabular}{|c|c|c|}
\hline Question & Answers & \\
\hline $\begin{array}{l}\text { Have you ever had a patient with a } \\
\text { pilonidal disease whom you treated } \\
\text { surgically? (Fig. 2 left) }\end{array}$ & $\begin{array}{l}\text { Yes } \\
\text { No }\end{array}$ & $\begin{array}{l}49 \\
2\end{array}$ \\
\hline $\begin{array}{l}\text { What methods have you used in the } \\
\text { treatment of pilonidal sinus? (Fig. } \\
2 \text { right) }\end{array}$ & $\begin{array}{l}\text { Drainage } \\
\text { Excision and leaving open } \\
\text { Excision + NPWT } \\
\text { Bascom II } \\
\text { Kardykais Method } \\
\text { Limberg Flap }\end{array}$ & $\begin{array}{l}29 \\
32 \\
13 \\
25 \\
10 \\
14\end{array}$ \\
\hline $\begin{array}{l}\text { Have you ever used NPWT to treat } \\
\text { a patient with a pilonidal disease? }\end{array}$ & $\begin{array}{l}\text { Yes } \\
\text { No }\end{array}$ & $\begin{array}{l}16 \\
32\end{array}$ \\
\hline $\begin{array}{l}\text { Which NPWT systems have you } \\
\text { used in the treatment of pilonidal } \\
\text { disease? }\end{array}$ & $\begin{array}{l}\text { Stationary - large device } \\
\text { with a canister } \\
\text { Disposable } \\
\text { Both }\end{array}$ & $\begin{array}{l}11 \\
6 \\
2\end{array}$ \\
\hline $\begin{array}{l}\text { Have you ever experienced any } \\
\text { problems with maintaining the } \\
\text { tightness of the vacuum dressing? } \\
\text { (Fig. 3 left) }\end{array}$ & $\begin{array}{l}\text { Never } \\
\text { Sometimes, without affecting } \\
\text { treatment } \\
\text { Often, complicated treatment } \\
\text { Always, almost always }\end{array}$ & $\begin{array}{l}10 \\
15 \\
13 \\
0\end{array}$ \\
\hline $\begin{array}{l}\text { Would you use a disposable NPWT } \\
\text { if the patient brought one with } \\
\text { him/her to the hospital for surgery? } \\
\text { (Fig. 3 right) }\end{array}$ & $\begin{array}{l}\text { Yes } \\
\text { No }\end{array}$ & $\begin{array}{l}45 \\
2\end{array}$ \\
\hline $\begin{array}{l}\text { How did you hear about the possi- } \\
\text { bility of using NPWT in the treat- } \\
\text { ment of pilonidal disease? }\end{array}$ & $\begin{array}{l}\text { Publication } \\
\text { Conference } \\
\text { Colleague } \\
\text { Advertisement } \\
\text { Personal Initiative } \\
\text { Patient }\end{array}$ & $\begin{array}{l}7 \\
23 \\
4 \\
6 \\
5 \\
0\end{array}$ \\
\hline
\end{tabular}

In March 2019, our department (The General and Endocrine Surgery and Gastroenterological Oncology Department of Heliodor Swiecicki Clinical Hospital at the Karol Marcinkowski Medical University in Poznan) organized a webinar for Polish surgeons on the subject of pilonidal disease that became the basis for a survey regarding the use of NPWT in the treatment of this disorder.

\section{Methods}

During an interactive online meeting (webinar) on the various methods used in the treatment of pilonidal disease, we invited 102 participants to complete a questionnaire created by our department. 51 webinar-participants chose to take part in our survey, 49 of which reported having operated on patients suffering from a pilonidal disease in the past (Fig. 2, left). The survey was comprised of multiple-choice questions (Tab. I)

Nearly all participants answered all the questions. It is worth noting that participants were able to choose more than one answer, and therefore we collected more answers than there were participants. The full survey, complete with questions and results is included in (Tab. I).

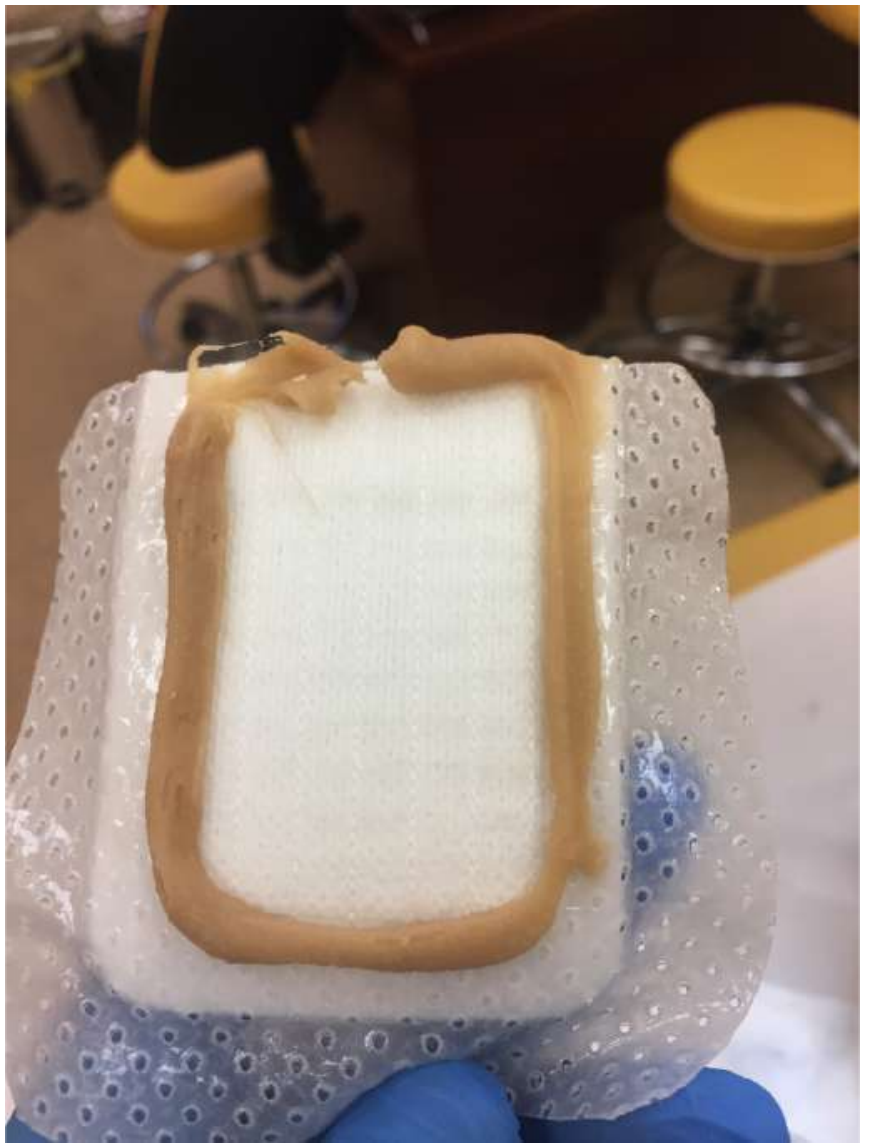

Figure 1. Ostomy paste (Stomahesive ${ }^{(R)}$ ConvaTec) was used around the margins of the hydrofiber dressings in order to achieve a better seal and improve the effectiveness of the NPWT course.

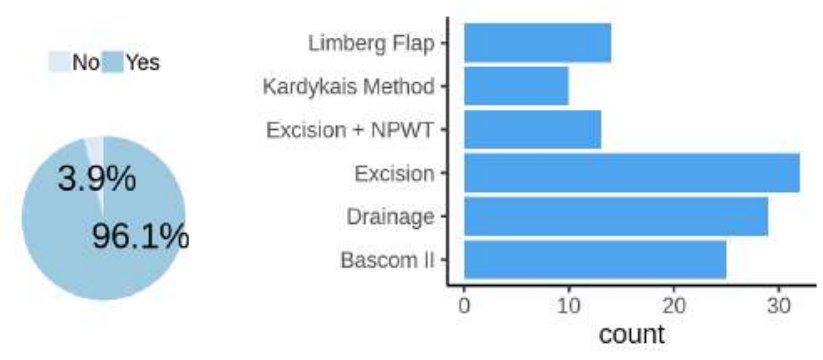

Figure 2. Have you ever had a patient with a pilonidal disease whom you treated surgically (left)? What methods have you used in the treatment of pilonidal sinus (right)?
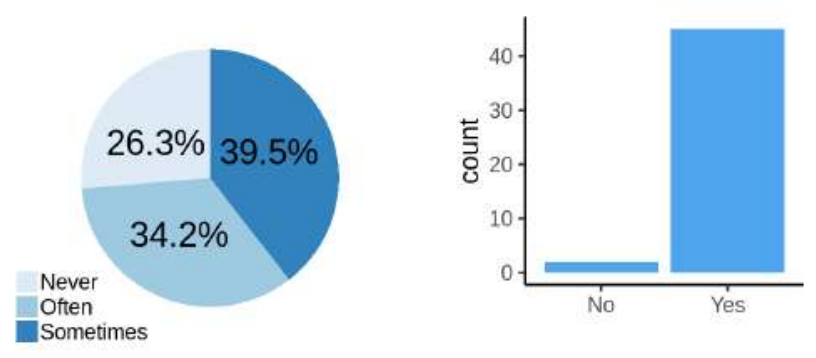

Figure 3. Have you ever experienced any problems with maintaining the tightness of the vacuum dressing (left)? Would you use a disposable NPWT if the patient brought one with him/her to the hospital for surgery (right)? 


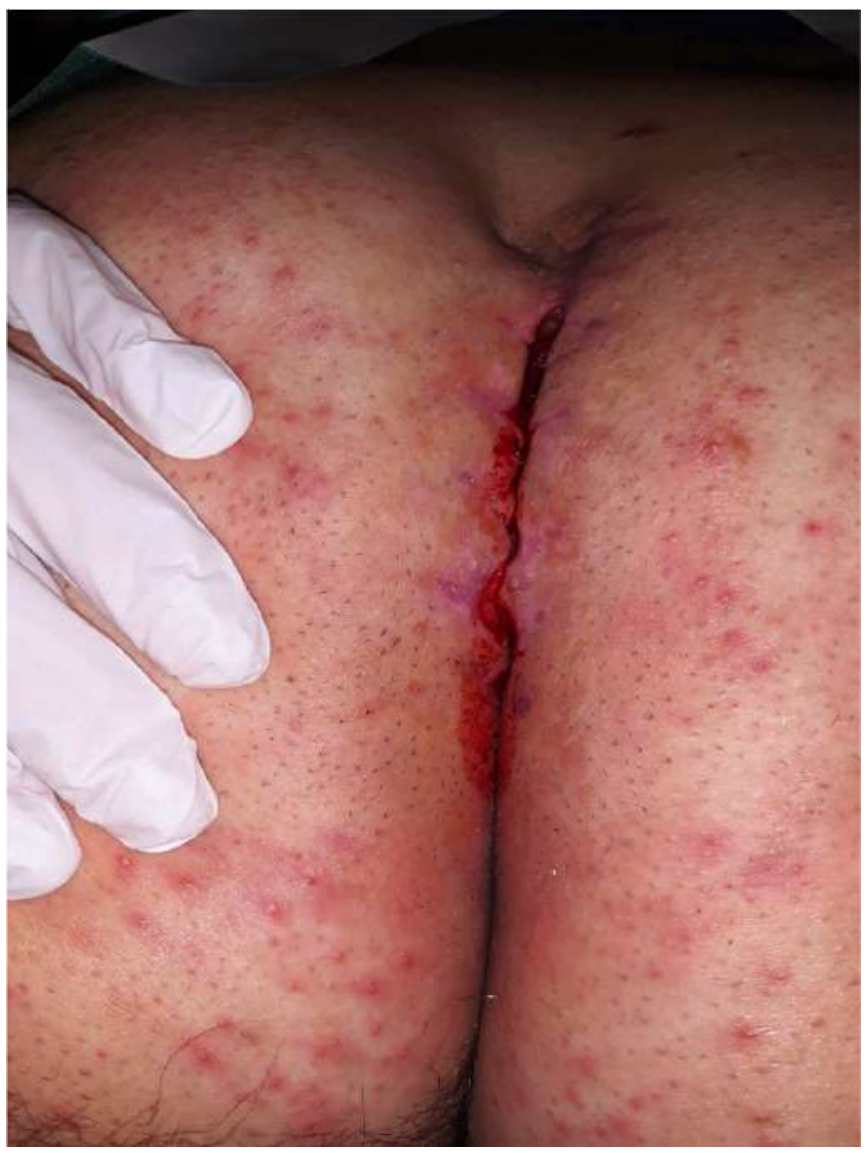

Figure 4. A pilonidal sinus was surgically removed with primary closure 2 months ago. Partial wound dehiscence with chronic inflammation of the surrounding skin can be observed. The lack of proper healing in this wound resulted in recurrent exudation, as well as chronic pain for the patient.

\section{Discussion AND ANALYSIS}

We successfully obtained information regarding the most frequently used operative methods in the treatment of pilonidal disease (Fig. 2, left). Our data show that respondents more commonly surgically excise the pilonidal sinus and leave the wound open, allowing it to heal by secondary intention. All resections with plastic surgery closures are used $50 \%$ less often. Although skin plastic surgical methods are outlined in the management recommendations, the difficulty of these procedures discourages surgeons, especially since the incidence of postoperative complications is similar to other methods.

A relatively large number of surgeons who use the combination of simple excision of the pilonidal sinus with NPWT (13/49) draws attention. This, compared to 16 out of 49 who responded positively when asked if they had ever used NPWT, indicates that surgeons are not only using NPWT to improve healing by stimulating granulation tissue production following pilonidal sinus excision, but also for secondary support of healing processes (possibly after other surgeries such as flap-plasty). Such a treatment course was described by Sukru et al. after a medical team was able to successfully treat wound dehiscence by applying NPWT. The dressing was changed 3 times every 3 days. On the 10th day NWPT

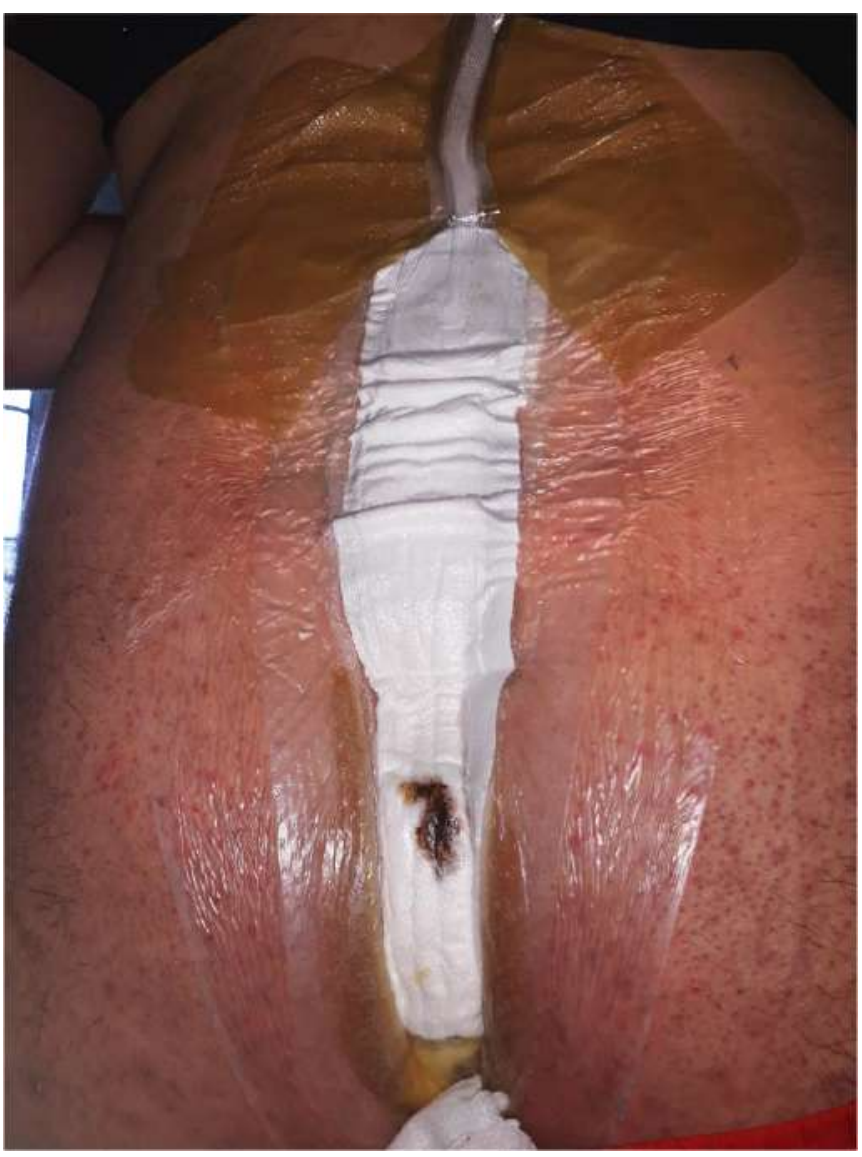

Figure 5. NPWT was introduced using Avelle ${ }^{T M}$ ConvaTec, UK. NPWT dressings were changed every 3-4 days, depending on the volume of exudation from the wound as well as the sealing of the vacuum.

was removed and the sutures were sewn in accordance with the skin-plasty made during the initial surgery. 13

Analysis of the reported procedures used in the treatment of pilonidal disease indicates that excision and open wound healing is the most common procedure (32/49). In our opinion, this is potentially the optimal group to support healing with NPWT. It seems that lack of NPWT use is not due to lack of knowledge or skills, but rather restricted access to NPWT devices and materials. This issue is indirectly associated with the lack of reimbursement for this form of treatment. It was interesting to find that 45 out of 49 respondents reported that they would employ the use of vacuum therapy system if a patient came to the hospital with his own disposable NPWT device (Fig. 3 , right).

It is worth noting that the majority of surgeons using NPWT are satisfied at maintaining the tightness and effectiveness of a vacuum dressing, what was initially considered a technical limitation of this method (Fig. 3. left). Only 13 out of 49 surgeons reported problems with NPWT sealing that complicated the course of treatment, compared to 25 out of 49 surgeons who reported that they had either no problems at all or problems that did not negatively impact patients' health outcomes (Fig. 3, right).

When it comes to the choice in NPWT systems, our data show that most surgeons still prefer to use stationary systems 


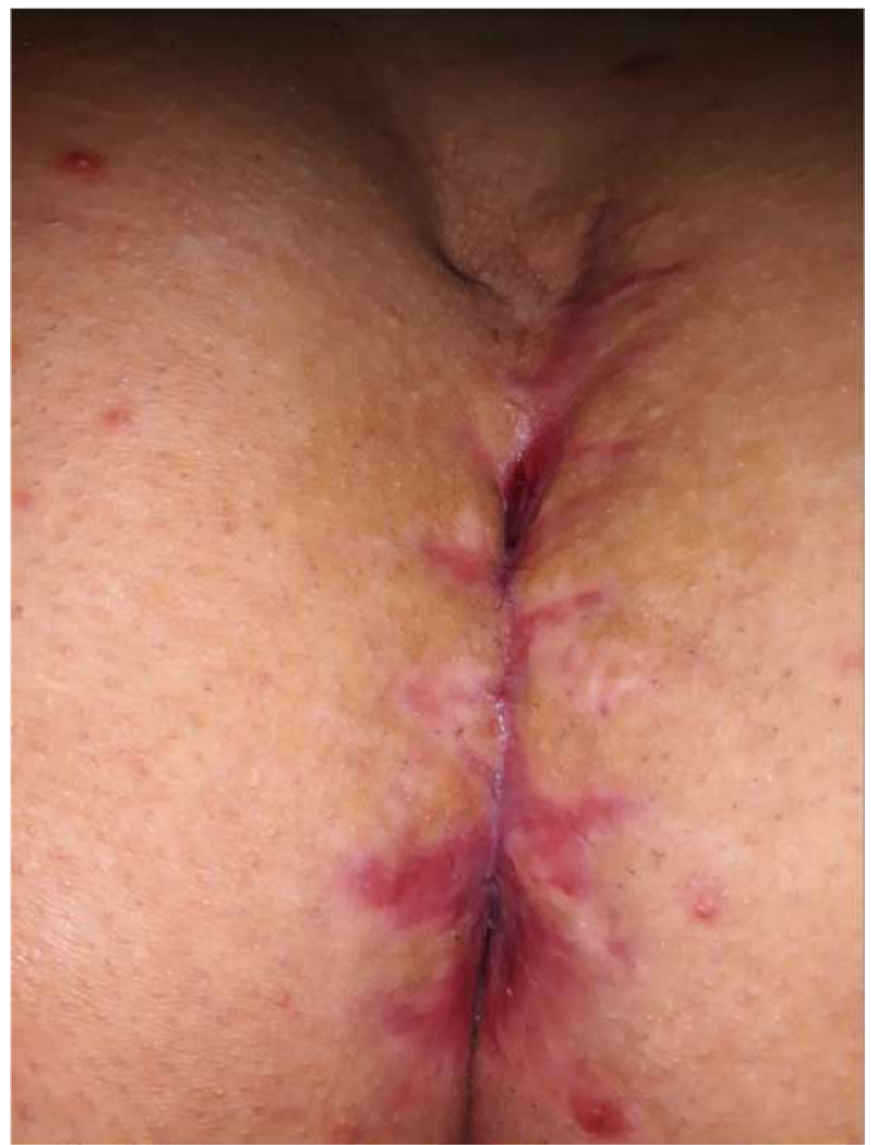

Figure 6. Following a 3 week period during which the patient underwent NPWT, a significant reduction in exudate, pain, and inflammation could be observed. Healing processed and the margins of the skin were closed over the majority of the wound. NPWT was not continued and further treatment of the wound was supportive, with typical wound dressings being regularly changed for the next 2 weeks, at which point final closure of the wound could be seen.

that are provided by some hospital departments. Single-use, disposable devices are less commonly used. It seems to be related to the lack of reimbursement, but the common opinion that NPWT is dedicated only to hard-to-heal wounds also impacts this decision. Research strongly supports the role of NPWT to prevent surgical site infections across high-risk patient-groups 15

Use of NPWT disposable systems after the pilonidal sinus surgery, due to the nature of the disease (chronic and extensive infection and location that makes the maintenance of proper hygiene difficult) is an example of preventing surgical site infection. Figures (Fig. 1, 4, - 6) give an anecdotal example of how the use of NPWT in the treatment of pilonidal cyst may contribute to the successful therapeutic outcome.

\section{CONCLUSION}

Our survey determined that knowledge regarding NPWT among surgeons for the treatment of pilonidal disease is increasing and there is a great potential in using this method, despite the low availability across the Polish hospitals. It seems that the simplicity of use and the effectiveness in the treatment of pilonidal disease should earn NPWT a position in recommendations and guidelines.

\section{REFERENCES}

[1] T. L. Hull and J. Wu, "Pilonidal disease," Surgical Clinics, vol. 82, no. 6, pp. 1169-1185, 2002.

[2] S. R. Steele, W. B. Perry, S. Mills, and W. D. Buie, "Practice parameters for the management of pilonidal disease," Diseases of the Colon \& Rectum, vol. 56, no. 9, pp. 1021-1027, 2013.

[3] I. Iesalnieks, A. Ommer, S. Petersen, D. Doll, and A. Herold, "German national guideline on the management of pilonidal disease," Langenbeck's archives of surgery, vol. 401, no. 5, pp. 599-609, 2016.

[4] D. Segre, M. Pozzo, R. Perinotti, and B. Roche, "The treatment of pilonidal disease: guidelines of the italian society of colorectal surgery (siccr)," Techniques in coloproctology, vol. 19, no. 10, pp. 607-613, 2015.

[5] L. U. Biter, G. M. Beck, G. H. Mannaerts, M. M. Stok, A. C. van der Ham, and B. A. Grotenhuis, "The use of negative-pressure wound therapy in pilonidal sinus disease: a randomized controlled trial comparing negative-pressure wound therapy versus standard open wound care after surgical excision," Diseases of the Colon \& Rectum vol. 57, no. 12, pp. 1406-1411, 2014.

[6] M. Duxbury, I. Finlay, M. Butcher, and A. Lambert, Journal of wound care, vol. 12, no. 9, pp. 355-355, 2003.

[7] J. G. McGuinness, D. C. Winter, and P. R. O'Connell, "Vacuumassisted closure of a complex pilonidal sinus," Diseases of the colon \& rectum, vol. 46, no. 2, pp. 274-276, 2003.

[8] S. Saad, E. Shakov, V. Sebastian, and A. Saad, "The use of wound vacuum-assisted closure system in the treatment of recurrent or complex pilonidal cyst disease: experience in 4 adolescent patients,' Internet J Surg, vol. 11, no. 1, pp. 1-4, 2007.

[9] F. P. Bendewald, R. R. Cima, D. R. Metcalf, and I. Hassan, "Using negative pressure wound therapy following surgery for complex pilonidal disease: a case series." Ostomy/wound management, vol. 53, no. 5, pp. 40-46, 2007.

[10] J. B. Lynch, A. J. Laing, and P. J. Regan, "Vacuum-assisted closure therapy: a new treatment option for recurrent pilonidal sinus disease. report of three cases," Diseases of the colon \& rectum, vol. 47, no. 6 , pp. 929-932, 2004.

[11] F. P. Bendewald and R. R. Cima, "Pilonidal disease," Clinics in colon and rectal surgery, vol. 20, no. 02, pp. 086-095, 2007.

[12] S. Tas, O. F. Ozkan, M. M. Ocakli, E. Arslan, A. Kiraz, and M. Karaayvaz, "Management of flap dehiscence after limberg procedure for recurrent pilonidal disease by negative pressure wound therapy (npwt)," ABCD. Arquivos Brasileiros de Cirurgia Digestiva (São Paulo), vol. 30, no. 1, pp. 73-74, 2017

[13] E. Bianchi, J. Lei, T. Adegboyega, S. S. Shih, M. Berrones, S. Purdy, and D. E. Rivadeneira, "Negative pressure wound therapy is beneficial in the treatment of pilonidal disease," Journal of the American College of Surgeons, vol. 227, no. 4, pp. e109-e110, 2018.

[14] T. Banasiewicz, A. Bobkiewicz, and M. Borejsza-Wysocki, "Portable vac therapy improve the results of the treatment of the pilonidal sinusrandomized prospective study," Polish Journal of Surgery, vol. 85, no. 7, pp. 371-376, 2013.

[15] V. Strugala and R. Martin, "Meta-analysis of comparative trials evaluating a prophylactic single-use negative pressure wound therapy system for the prevention of surgical site complications," Surgical infections, vol. 18, no. 7, pp. 810-819, 2017.

[16] A. M. Bonds, T. K. Novick, J. B. Dietert, F. Y. Araghizadeh, and C. H. Olson, "Incisional negative pressure wound therapy significantly reduces surgical site infection in open colorectal surgery," Diseases of the Colon \& Rectum, vol. 56, no. 12, pp. 1403-1408, 2013.

[17] G. Pellino, G. Sciaudone, G. Candilio, G. S. De Fatico, I. Landino, A. Della Corte, R. Guerniero, R. Benevento, A. Santoriello, F. Campitiello et al., "Preventive npwt over closed incisions in general surgery: does age matter?" International Journal of Surgery, vol. 12, pp. S64S68, 2014 